\title{
Risk of opioid misuse in chronic non-cancer pain in primary care patients - a cross sectional study
}

\author{
Johannes Maximilian Just ${ }^{1 *}$ D, Linda Bingener ${ }^{1}$, Markus Bleckwenn ${ }^{1}$, Rieke Schnakenberg ${ }^{1,2}$ and Klaus Weckbecker ${ }^{1}$
}

\begin{abstract}
Background: Efforts to improve treatment of pain using opioids have to adequately take into account their therapeutic shortcomings which involve addictiveness. While there are no signs of an "opioid epidemic" in Germany similar to that in the US, there is little data on the prevalence of prescription opioid misuse and addiction. Therefore, our objective was to screen primary care patients on long-term opioid therapy for signs of misuse of prescription opioids.

Methods: We recruited 15 GPs practices and asked all patients on long-term opioid therapy (> 6 months) to fill out a questionnaire including the "Current Opioid Misuse Measure" (COMM $\left.{ }^{\circledast}\right)$, a self-report questionnaire. Patients with a malignant disease were excluded.

Results: $N=91$ patients participated in the study (response rate: 75.2\%). A third (31.5\%) showed a positive COMM ${ }^{\circledR}$ Score which represents a high risk of aberrant drug behaviour. A positive $\mathrm{COMM}^{\circledR}$ - Score showed a statistically significant correlation with a lifetime diagnosis of depression and neck pain.

Conclusions: While Germany does not face an "opioid eoidemic", addictiveness of opioids should be considered when using them in chronic non-tumor pain. In our study population, almost every third patient was at risk and should therefore be followed up closely. Co-prevalence of depression is a significant issue and should always be screened for in patients with chronic pain, especially thus with aberrant drug behaviour.
\end{abstract}

Keywords: Opioid, Misuse, Addiction, Prescription drugs, Prevalence

\section{Background}

Opioids are a cornerstone in the treatment of acute and chronic pain, still their therapeutic shortcoming have to be considered [1]. They involve risk of addiction, a narrow therapeutic ratio and lack of documented effectiveness in the treatment of several aspects of chronic non-cancer pain (CNCP) [2]. Misuse and addiction from prescription opioids is a serious public health issue in the US. The death toll has almost quadrupled in the 21st century, matching a similar increase in prescription rates $[2,3]$. A meta-analysis calculated an average proportion of misuse between 21 and 29\% (range, 95\% confidence interval [CI]: 13-38\%) for patients with CNCP [4].

\footnotetext{
* Correspondence: johannes.just@ukbonn.de

${ }^{1}$ Institute of General Practice and Family Medicine, Bonn University Clinic,

Sigmund-Freud-Street 25, 53127 Bonn, Germany

Full list of author information is available at the end of the article
}

Currently, significant effort is put into reversing these effects, including a new CDC guideline for "Prescribing Opioids for Chronic Pain" [2].

The increase of opioid prescription in the US is paralleled by an increase in all European countries [5]. A meta-analysis on medication misuse in the EU named prescription opioids as a main group of misuse but data on mortality directly linked to opioids does not exist in Germany [6]. The increase in opioid prescriptions in Germany is clearly less extreme than in the US. The percentage of persons with statutory health insurance who have been prescribed opioids at least once per year has increased from $3.3 \%$ in 2000 to $4.5 \%$ in 2010 [7]. An analysis of randomly selected claims records of 870,000 persons in a large German medical health insurance organization showed a pooled 1-year prevalence of abuse/addiction (defined as hospital stays related to

(c) The Author(s). 2018 Open Access This article is distributed under the terms of the Creative Commons Attribution 4.0 International License (http://creativecommons.org/licenses/by/4.0/), which permits unrestricted use, distribution, and 
addiction) of $0.008 \%$ in those on long-term opioid therapy (LTOT). Therefore, the authors concluded, that "there are no signals of an 'opioid epidemic' in Germany" [8].

Factors that may have contributed to the opioid epidemic in the US include higher doses of opioids per patient compared to other developed countries, a high individual health care cost burden, lesser regulatory restrictions for opioids and a "pro-profit" orientation of key elements of the health care system [9-11]. The German medical system on the contrary offers compulsory, high-quality health care with adequate regulatory restrictions for opioids including a ban on direct to consumer marketing by the pharmaceutical industry.

The lack of many society related contributing factors to opioid misuse in Germany is reassuring. Nevertheless addictive behaviour is a world-wide problem and more data on possible at-risk patients in Germany could help to keep rates of opioid misuse low. Therefore we conducted a study, screening primary care patients on LTOT for risk of misuse of prescription opioids, using a validated self-report measure [12].

\section{Methods}

We conducted a cross sectional study at GP's practices using the self-report questionnaire Current Opioid Misuse Measure $\left(\mathrm{COMM}^{\circ}\right)$, adding items concerning the medical history as well as socio-economic information. $\mathrm{COMM}^{\ominus}$ Score results were the primary outcome criterion.

The $\mathrm{COMM}^{\circ}$ Score is a self-report questionnaire for patients using opioids longer than six months. We used an existing German version of the $\mathrm{COMM}^{\circ}$. The questionnaire was translated from English to German by experienced translators using the "back-translation method". Then, a team of bilingual addiction experts fine-tuned the questionnaire in order to make sure that the meaning and intent of the original items were preserved [13]. Later, it was pre-tested for comprehensibility and acceptability with five representative patients by our study group, using cognitive interviewing techniques.

In order to recruit GPs, we contacted all GPs in the greater Bonn area $(>100)$ via fax and telephone. We stopped recruiting after having reached the planned number of 15 GPs. A total of four GPs refused to participate due to their high workload.

All patients on LTOT (> 6 months) for CNCP, who entered the practice to collect their prescription, were asked to fill in the questionnaire by the front desk staff. The study period was three months, as it represents the maximum duration of one prescription in Germany, making sure we included all relevant patients. Those who did not want to participate were asked to fill in their age and sex to test for differences in participants and nonparticipants.

Inclusion criteria were LTOT (> 6 months) for CNCP and sufficient literacy. Excluded were patients with malignant disease, patients who could not collect their prescription themselves due to age or multimorbidity and patients on opioid-maintenance therapy.

The data management was performed at the Department of General Practice and Family Medicine in Bonn and included data entry, data validation by plausibility checks, frequency analyses and advanced statistics using IBM SPSS Statistics $22^{\circ}$. We used exploratory statistics and a multiple logistic regression model with a dichotomous dependent variable to describe data and to explore the relationship between dependent and independent variables. For comparison of participants and nonparticipants concerning age and sex, we used Student's t-test and Pearson's chi-squared test.

The anonymous survey received ethical approval by the Ethics Committee of the Medical Faculty of the University of Bonn (No. 243/16).

\section{Results}

The inclusion criteria were met by 121 patients from 12 GPs practices, of which 91 completed the questionnaire (response rate: $75.2 \%$ ). Participants mean $\mathrm{COMM}^{\circ}$ - Score was 7.26 (min-max: 0-41).

On average, we received nine (min - max: 0-17) questionnaires per practice. One practice claimed they did not have any patients matching our criteria, two practices did not proceed with the study due to "work overload" and were therefore considered "drop-outs" (rate: 13\%).

All of the non-participants agreed to have their age and sex documented. Non-participants differed slightly from participants concerning age and sex, without differences being statistically significant (Table 1 ).

The mean age of participants was 69.70 years (SD 14.39), 62.4\% were female. Most participants reported back and joint pain as the reason for taking opioid analgesics. The proportion of participants with a "high risk of aberrant drug behaviour" according to $\mathrm{COMM}^{\circ}$ (meaning a score of nine or higher) was $31.5 \%$. Of these patients, $64.3 \%$ had a high school education only. A statistically significant correlation with a positive $\mathrm{COMM}^{\circ}$ - Score was present for the variables "lifetime diagnosis of depression" and "neck pain". A detailed description of all variables and the connected odds ratio for a positive $\mathrm{COMM}^{\circ}$-Score is given in Table 2 .

We used a multiple regression model to control for statistically significant correlations between positive $\mathrm{COMM}^{\circ}$ - Scores and the documented patient characteristics. The model was sound, showing a Nagelkerke's Pseudo- $R^{2}$ of 0.401 . All tested variables are shown in Table 2. 
Table 1 Age and sex distribution for participants and nonparticipants

\begin{tabular}{llll}
\hline Variable & All participants $(n=93)$ & $\begin{array}{l}\text { Non participants } \\
(n=28)\end{array}$ & Difference significant \\
\hline Age (mean) & 69.70 (SD: 14.39; min/max: 25/93) & 74.79 (SD: 14.06; min/max: 46/92) & No $^{\mathrm{a}}$ \\
Sex: female & $62.4 \%$ & $60.7 \%$ & No $^{\mathrm{b}}$ \\
\hline
\end{tabular}

${ }^{\text {a }}$ Student's t-test (df: 119)

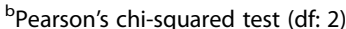

\section{Discussion}

Our study showed a high risk of aberrant drug behaviour in almost one third (31.5\%) of the targeted patient group. With $75.2 \%$, the response rate was good. Back and joint pain were the most commonly reported reasons for taking opioid painkillers. A statistically significant correlation with a positive $\mathrm{COMM}^{\circ}$ - Score was present for the variables "lifetime diagnosis of depression" and "neck pain".

The proportion of "at risk patients" seems rather high, regarding the assumption that there is no opioid epidemic in Germany. In this context it needs to be emphasized, that we screened for patients how are at risk of developing misuse only. So there probably is potential for an opioid epidemic in Germany, but positive physician- and society related factors might have prevented such a development.

The proportion of "at risk" patients may have been overestimated in our study. The $\mathrm{COMM}^{\bullet}$ - Score uses several questions that target signs of emotional volatility that might be present in depression as well as in opioid misuse. As depression is more prevalent in patients with $\mathrm{CNCP}$, this might explain the high proportion of $\mathrm{COMM}^{\circ}$ - Score positive patients in the sample. Additionally, this may also explain the high proportion of patients with depression within the group of $\mathrm{COMM}^{\bullet}$ - Score positive patients. More than half of $\mathrm{COMM}^{\circ}$ - Score positive participants reported a history of a diagnosis of depression (60.7\%) with a statistically significant correlation between a positive score and the presence of depression. The average lifetime prevalence of depression in Germany in contrast is $11.6 \%$, the prevalence of depression in a large European chronic pain patient cohort was $21 \%[14,15]$. So while the methodology does not allow us to make a statement concerning causality, and there might be a bias towards over-diagnosing risk of misuse in patients with depression, the high prevalence of depression should be kept in mind when treating patients with opioid misuse.

Some known risk factors connected to the opioid epidemic from prior studies in the US were not found in our study population (e.g. young age, male sex). [16, 17]. So the particularly alarming increase in opioid misuse in young, male subjects in the US seems not to be an issue in our sample group [18]. Numbers for "prior addiction diagnosis" and "addiction diagnosis in relatives" were very small $(n<5)$ in our study, which explains non-significant results for these well described risk factors.

The statistically significant correlation of neck pain and a positive $\mathrm{COMM}^{\circ}$ - Score in the logistic regression model is

Table 2 Risk factors for positive COMM - Score (logistic regression analysis, $n=91, \mathrm{df}=14$ )

\begin{tabular}{|c|c|c|c|c|}
\hline & CommScore positive & CommScore negative & OR $(95 \% \mathrm{Cl})$ & Sig. \\
\hline $\mathrm{N}(\%)$ & $28(31.5 \%)$ & $65(60.5 \%)$ & $\mathrm{N} / \mathrm{A}$ & $\mathrm{N} / \mathrm{A}$ \\
\hline Gender, male & $9(32.1 \%)$ & $25(39.1 \%)$ & $0.85(0.25-2.87)$ & 0.79 \\
\hline Age (mean (SD)) & $69.61(17.2)$ & $69.74(13.2)$ & $0.99(0.95-1.04)$ & 0.69 \\
\hline Headache & $5(17.9 \%)$ & $6(9.2 \%)$ & $1.80(0.27-12.19)$ & 0.55 \\
\hline Back pain & $23(82.1 \%)$ & $43(66.2 \%)$ & $1.45(0.37-5.65)$ & 0.60 \\
\hline Joint pain & $17(60.7 \%)$ & $30(46.2 \%)$ & $2.70(0.72-10.16)$ & 0.14 \\
\hline Neck pain & $10(35.7 \%)$ & $7(10.8 \%)$ & $9.23(1.63-52.26)$ & 0.01 \\
\hline Rheumatic pain & $7(25.0 \%)$ & $11(16.9 \%)$ & $0.94(0.20-4.53)$ & 0.94 \\
\hline Postoperative pain & $5(17.9 \%)$ & $10(15.4 \%)$ & $0.57(0.12-2.75)$ & 0.48 \\
\hline Other pain & $4(14.3 \%)$ & $11(16.9 \%)$ & $0.28(0.04-1.92)$ & 0.19 \\
\hline Prior addiction diagnosis & $2(7.1 \%)$ & $2(3.1 \%)$ & $1.34(0.11-16.99)$ & 0.82 \\
\hline Addiction diagnosis in family & $3(10.7 \%)$ & $4(6.2 \%)$ & $5.55(0.61-50.61)$ & 0.13 \\
\hline Depression & $17(60.7 \%)$ & $16(25 \%)$ & $6.84(1.88-24.91)$ & 0.004 \\
\hline Fear of Addiction & 11 (39.3\%) & $18(27.7 \%)$ & $0.85(0.24-3.06)$ & 0.80 \\
\hline Education, high school or lower & $18(64.3 \%)$ & $27(41.5 \%)$ & $3.13(0.92-10.62)$ & 0.07 \\
\hline
\end{tabular}

$\mathrm{N}=$ absolute number of participants; $(\%)=$ percentage within variable COMM - Score; OR=Odds ratio; $(95 \% \mathrm{Cl})=95 \% \mathrm{Confidence} \mathrm{Interval} \mathrm{for} \mathrm{Odds} \mathrm{ratio,}$ Sig. = Significance of OR 
an interesting new finding. Psychosocial stress factors may have acted as a confounding factor, as they are contributing factors to both, substance abuse and neck pain [19-21]. Still, numbers are small and it would be interesting if our findings can be reproduced in larger samples for instance using secondary analysis of a large insurance database.

There are several further limitations to this study. It is difficult to control for bias that stems from different prescription patterns in doctors and we did only include patients from 12 different GPs practices. So we cannot claim that our sample is representative. Still they give a first hint at which proportion of opioid misuse in CNCP can be expected on a national level. The sample group of GP practices can be considered a convenience sample. While we did contact all GPs in the area, we did not randomly choose from those willing to participate. We did so to achieve higher numbers of participants but this could have led to a selection bias.

Generally, the Bonn area has a high socio-economic status, so we controlled for this factor using educational status as an indicator and tried to achieve socio-economic heterogeneity concerning the location of the participating practices. As shown in Table 2, there was no significant difference between $\mathrm{COMM}^{\circ}$ - Score positive and negative patients in relation to their educational status. Furthermore, age adjusted average educational levels in Germany did not differ greatly when compared with the group of $\mathrm{COMM}^{\circ}$ - Score positive patients (basic high school education or lower in $\mathrm{COMM}^{\circ}$ - Score positive patients: 64.3\%, age adjusted German average: 59.9\%) [22].

The $\mathrm{COMM}^{\circ}$ is a reliable and valid screening tool to help detect current aberrant drug-related behaviour among chronic pain patients [12]. We used a thorough method of translation and German language adaptation. Data from China suggests that the $\mathrm{COMM}^{\circ}$ shows satisfactory reliability and validity, despite the arguably high cultural gap between China and the US [23]. Still it is a shortcoming of this study, that we did not perform tests for internal consistency, test-retest reliability, exploratory factor analysis and confirmatory factor analysis.

\section{Conclusion}

In summary, our study showed that $31.5 \%$ of patients with CNCP on LTOT in Germany might be at a high risk for aberrant drug behaviour. This does not signify that these patients are addicted yet, albeit their risk is probably increased. Considering opioids shortcomings (low therapeutic ratio, lack of documented effectiveness in the treatment of several aspects of chronic non-cancer pain), these at risk patients should be followed up regularly. Depression should always be screened for and treated in CNCP and the high co-incidence of addiction risk and depression should be acknowledged when doing so.

\section{Abbreviations}

CNCP: Chronic non-cancer pain; $\mathrm{COMM}^{\oplus}$ : Current opioid misuse measure; LTOT: Long-term opioid therapy

\section{Acknowledgements}

We thank Inflexxion ${ }^{\text {TM }}$ for giving their consent to use the $\mathrm{COMM}^{\oplus}$ in this study. We thank Indivior Germany ${ }^{\text {TM }}$ for allowing us to use their german translation of the $\mathrm{COMM}^{\circledast}$.

Availability of data and materials

All data used is available through the authors upon request.

\section{Authors' contributions}

JMJ designed the study with LB and drafted main parts of the paper. LB gathered data, performed statistical analysis and contributed to the development of the paper. MB contributed to the development of the paper. RS gave support in statistical analysis and helped drafting the paper. KW had the initial idea and helped drafting the final paper. All authors read and approved the final manuscript.

\section{Ethics approval and consent to participate}

The study was carried out under the declaration of Helsinki. It received ethical approval by the Ethics Committee of the Medical Faculty of the University of Bonn (No. 243/16). Participants received oral and written information on the study as well as the questionnaire. They were then given the option to put an empty or filled out anonymous questionnaire in a sealed box which was later handed over to the researchers. This procedure was used to give patients the opportunity of non-participation without being revealed. The return of a completed questionnaire was then interpreted as informed consent obtained from participants.

\section{Competing interests}

Indivior Germany ${ }^{\mathrm{TM}}$ gave us consent to use their translation of the $\mathrm{COMM}^{\circledR}$ thereby saving us the effort of high-quality translation. Klaus Weckbecker was a member of the advisory board of Indivior Germany ${ }^{\mathrm{TM}}$, manufacturer of Buprenorphine, a treatment option for opioid addiction. Additionally he received fees for lectures on addiction medicine from the same company. He has terminated these activities in 2015

All other authors declare no conflict of interest.

\section{Publisher's Note}

Springer Nature remains neutral with regard to jurisdictional claims in published maps and institutional affiliations.

\section{Author details}

${ }^{1}$ Institute of General Practice and Family Medicine, Bonn University Clinic, Sigmund-Freud-Street 25, 53127 Bonn, Germany. ${ }^{2}$ Department for Health Services Research, Carl von Ossietzky Universität Oldenburg, Post office box 2503, 26111 Oldenburg, Germany.

Received: 3 July 2017 Accepted: 25 May 2018

Published online: 20 June 2018

References

1. WHO Model Lists of Essential Medicines [Internet]. [cited 2017 Jun 30]. Available from: http://www.who.int/medicines/publications/ essentialmedicines/EML_2017_ExecutiveSummary.pdf?ua=1

2. Frieden TR, Houry D. Reducing the Risks of Relief - The CDC OpioidPrescribing Guideline. N Engl J Med. 2016;374:1501-4.

3. National Institute on Drug Abuse: Overdose Death Rates [Internet]. [cited 2017 Jan 11]. Available from: https://www.drugabuse.gov/related-topics/ trends-statistics/overdose-death-rates

4. Vowles KE, McEntee ML, Julnes PS, Frohe T, Ney JP, van der Goes DN. Rates of opioid misuse, abuse, and addiction in chronic pain: a systematic review and data synthesis. Pain. 2015;156:569-76.

5. Website [Internet]. [cited 2017 Aug 15]. Available from: Narcotic Drugs Technical Reports [Internet]. International Narcotics Control Board. [cited 2017 Jun 7] ; Available from: https://www.incb.org/incb/en/narcotic-drugs/

6. Casati A, Sedefov R, Pfeiffer-Gerschel T. Misuse of medicines in the European Union: a systematic review of the literature. Eur Addict Res. 2012;18:228-45. 
7. Schubert I, Ihle P, Sabatowski R. Increase in opiate prescription in Germany between 2000 and 2010: a study based on insurance data. Dtsch Arztebl Int. 2013;110:45-51.

8. Marschall U, L'hoest H, Radbruch L, Häuser W. Long-term opioid therapy for chronic non-cancer pain in Germany. Eur J Pain. 2016;20:767-76.

9. Fischer B, Keates A, Bühringer G, Reimer J, Rehm J. Non-medical use of prescription opioids and prescription opioid-related harms: why so markedly higher in North America compared to the rest of the world? Addiction. 2014;109:177-81.

10. Häuser W, Petzke F, Radbruch L, Tölle TR. The opioid epidemic and the long-term opioid therapy for chronic noncancer pain revisited: a transatlantic perspective. Pain Manag. 2016;6:249-63.

11. Sullivan MD, Howe CQ. Opioid therapy for chronic pain in the United States: promises and perils. Pain. 2013;154(Suppl 1):S94-100.

12. Butler SF, Budman SH, Fanciullo GJ, Jamison RN. Cross validation of the current opioid misuse measure to monitor chronic pain patients on opioid therapy. Clin J Pain. 2010;26:770-6.

13. Sperber AD. Translation and validation of study instruments for crosscultural research. Gastroenterology. 2004;126:S124-8.

14. Busch MA, Maske UE, Ryl L, Schlack R, Hapke U. Prävalenz von depressiver Symptomatik und diagnostizierter Depression bei Erwachsenen in Deutschland. Bundesgesundheitsblatt - Gesundheitsforschung Gesundheitsschutz. 2013;56:733-9.

15. Breivik H, Collett B, Ventafridda V, Cohen R, Gallacher D. Survey of chronic pain in Europe: Prevalence, impact on daily life, and treatment. Eur J Pain. 2006;10:287.

16. Edlund MJ, Martin BC, Fan M-Y, Devries A, Braden JB, Sullivan MD. Risks for opioid abuse and dependence among recipients of chronic opioid therapy: Results from the TROUP Study. Drug Alcohol Depend. 2010;112:90-8.

17. Turk DC, Swanson KS, Gatchel RJ. Predicting opioid misuse by chronic pain patients: a systematic review and literature synthesis. Clin J Pain. 2008;24:497-508.

18. National Institute on Drug Abuse. America's Addiction to Opioids: Heroin and Prescription Drug Abuse [Internet]. [cited 2017 Mar 29]. Available from: https:/ www.drugabuse.gov/about-nida/legislative-activities/testimony-to-congress.

19. Hush JM, Michaleff Z, Maher CG, Refshauge K. Individual, physical and psychological risk factors for neck pain in Australian office workers: a 1-year longitudinal study. Eur Spine J. 2009;18:1532-40.

20. Fricton JR, Kroening R, Haley D, Siegert R. Myofascial pain syndrome of the head and neck: a review of clinical characteristics of 164 patients. Oral Surg Oral Med Oral Pathol. 1985;60:615-23.

21. Cohen SP, Hooten WM. Advances in the diagnosis and management of neck pain. BMJ. 2017;358:3221

22. DESTATIS - German Statistics Agency [Internet]. [cited 2017 Aug 24]. Available from: https://www.destatis.de/DE/Publikationen/Thematisch/ BildungForschungKultur/Bildungsstand/ BildungsstandBevoelkerung5210002167004.pdf? blob=publicationFile

23. Zhao Y, Li Y, Zhang X, Lou F. Translation and validation of the Chinese version of the Current Opioid Misuse Measure (COMM) for patients with chronic pain in Mainland China. Health Qual Life Outcomes. 2015;13:147.

\section{Ready to submit your research? Choose BMC and benefit from:}

- fast, convenient online submission

- thorough peer review by experienced researchers in your field

- rapid publication on acceptance

- support for research data, including large and complex data types

- gold Open Access which fosters wider collaboration and increased citations - maximum visibility for your research: over $100 \mathrm{M}$ website views per year

At BMC, research is always in progress.

Learn more biomedcentral.com/submissions 